Study of sedimentary rocks

Principles of Sedimentology. By G. M. Friedman and J. E. Sanders. Pp. 792. (Wiley: Chichester, UK, and New York, 1978.) £15.75.

THERE is no doubt that this book is a major benchmark in the study of sedimentary rocks similar to the publication of Pettijohn's Sedimentary Rocks in 1949.

Principles of Sedimentology is divided into six parts of fourteen chapters, five complements, a glossary, a bibliography and a subject index. Part I reviews the scope, evolution, techniques and philosophy of sedimentology. Part II describes sedimentary particles. The text has been divided into two courses, course 1 for innumerate, and course 2 for numerate students. As only six pages are considered too mathematical for many students this seems an unnecessary distinction which will increase the neuroses of innumerate readers. Part III deals with sedimentary processes, including deposition and diagenesis. Part IV is concerned with the classification and nomenclature of sedimentary rocks and Part $\mathrm{V}$ describes modern depositional environments and the environmental diagnosis of ancient sedimentary rocks. Part VI relates sedimentology to stratigraphy and includes a useful review of the relationship between sedimentation and plate tectonics and an introduction to wireline logs including the Dipmeter.

The next 90 pages of the book consist of sections titled "Complements" A to E. These are actually a series of chapters describing modern depositional processes and environments, including deltas, tidal flats and turbidites. This seems an odd arrangement, as most of this material logically belongs either in Part III (Sedimentary Processes) or Part V (Modern Sedimentary Environments).

The "Complements" are followed by a 22-page glossary which is totally unnecessary. One of the many good points of this book is that each new term is printed in bold face type followed by a definition in italic face. This arrangement, coupled with the excellent index, renders a glossary superfluous. Many of the terms included seem unnecessary-for example, "upwelling, viscocity, wadi, surface texture, stuffed basin (sic), veryshallow-water wave"; and does one really need to know that the bushmen of the Kalahari desert call a valley "omiribi"?

The glossary is followed by a biblio- graphy which is nearly 200 pages long. in their preface the authors say that, in response to popular demand, they have not followed the custom of quoting authors and dates at appropriate places in the text coupled with full bibliographies at the conclusion of each chapter. Instead, sections of text are punctuated by lists of names and dates, but not paper titles. Thus the reader must refer to the terminal bibliography to discover the titles of recommended books and papers. Each chapter then concludes with a short reading list. Though the bibliography is very comprehensive the selected reading lists are less so. It seems strange that, for example, Allen's Physical Processes of Sedimentation and Wilson's Carbonate Facies in Geologic History are not suggested for further reading at the appropriate places in the text. The bibliography itself is excellent and includes citations up to 1977. An odd

\section{Elementary meteorology}

Elementary Meteorology: A Course. By The Meteorological Office. Second edition. Pp. 208. (Her Majesty's Stationery Office: London, UK, 1978.) £4.95.

IT is probably not too unfair to say that this book was intended for the education of entrants to the Meteorological Office and is being offered for sale to the general public as a bonus. Perhaps it helps to show that the Ministry of Defence is not only concerned with things secret.

Explicitly, the book is aimed at "weather observers with a background of physics equivalent to that of Ordinary level of the General Certificate of Education"; they will indeed find here much of use and interest.

Chapters on temperature, pressure, water vapour and clouds start from basic physical principles and go on to consider in some detail methods of observation and classification. Chapters on precipitation, thunderstorms and optical phenomena are more descriptive of the processes at work, but the chapter on synoptic meteorology owes much to the early origin of the book and concentrates on correct identification and classification. Forecasting, radar and satellite observation are mentioned briefly. It is a pity that the two rather nice satellite pictures were not dated and do not have an accompanying synoptic analysis.

For this observer, with ordinary level physics, wanting to familiarise himself with meteorological practice and jargon, it is good value for money. feature of this is the frequent use of the term "( $\mathrm{sic})$ " at an average rate of once a page throughout the bibliography.

Considered overall, the book is compnehensive, accurate, well written and excellently illustrated. Students' minds will not be overtaxed by monotonous slabs of text. Every page contains an illustration or heading to break the monotony. Wiley are to be congratulated for producing a book of this magnitude for a mere $£ 15.75$.

Despite the eccentric arrangement of its material there is no doubt that this book will be invaluable to sedimentologists, students, teachers, and industrial geologists working with sedimentary rocks.

\section{R. C. Selley}

R. C. Selley is Reader in Petroleum Geology at Imperial College, University of London, UK.

Where else can you find Regnault's equation, the precise authoritative distinction between fog, mist and haze, the definition of $\mathrm{Ci}$ spi cgen (no kidding-p81) and much else, for less than $£ 5$.

Mind, HMSO does manage to produce an incredibly dull combination of typeface and layout that just shrieks 'educational manual', as you open any page. They do not do justice to Pedgley's nice pictures either.

The book is not suitable for the inquisitive, advanced, student who wants to find out what science there is in meteorology-it does not pretend to be and is not, an introductory text. There are too many silly mistakes, like saying the pressure "in pascals" is given by weight/area, whereas the relationship is true whatever units it is measured in; and that is pretty fundamental physics.

It is ludicrously parochial for a general reader, referring, as nearly as it can, only to weather over the British Isles. Office publications and research are similarly oversold. There is a delightful bit in the Introduction that lists "research into the microphysics of clouds" as one of two "great advances in meteorological knowledge since 1938"- -few meteorologists would agree with such an extravagant appraisal. It saddens me to see that the exciting new concepts that have been developed by modern science are going to find their way so slowly and capriciously into the meteorological services.

J. S. A. Green

J. S. A. Green is Head of the Atmospheric Physics Group at Imperial College, University of London, UK. 